\title{
Clinical value of radionuclide oesophageal transit measurement
}

\author{
J S DE CAESTECKER, J N BLACKWELL, R D ADAM, W J HANNAN, JOAN BROWN, \\ AND R C HEADING \\ From the Department of Medicine, Department of Radiology and Department of Medical Physics, Royal \\ Infirmary, Edinburgh
}

SUMMARY We have reviewed our experience of 150 patients to assess the clinical value of radionuclide oesophageal transit measurements in relation to established oesophageal motility investigations. Achalasia and conditions characterised by incoordinate oesophageal motor activity were detected with equal frequency by manometry and radionuclide transit measurement. Radionuclide transit measurements identified abnormalities not detected by manometry in 18 patients, and manometry was abnormal in 26 patients with normal radionuclide studies, including all patients with nutcracker oesophagus and most with hypertensive lower oesophageal sphincter. The overall sensitivity of radionuclide transit measurements in detecting oesophageal dysmotility was $75 \%$, the sensitivity of manometry was $83 \%$ and that of conventional barium radiology $30 \%$. We conclude that radionuclide transit measurement is a useful test for patients with suspected oesophageal motility disorders. Although it has limitations as a screening test, it provides additional information which complements oesophageal manometry.

Radionuclide transit measurement has been proposed as a sensitive screening test for oesophageal dysmotility. ${ }^{2}$ The attraction lies in the rapidity of its performance, the easily quantifiable results and its non-invasive nature. Tolin and coworkers first reported use of this technique in patients with oesophageal motility disorders, describing a method to measure transit time through the whole oesophagus. ${ }^{3} \mathrm{~A}$ modification in which the oesophagus is subdivided into three areas of interest was utilised by Russell and colleagues. ' This has the advantage of providing more detailed information of the pattern of transit of the fluid bolus through the oesophagus, and has demonstrated abnormalities in symptomatic patients in whom conventional radiology and manometry were normal. This implies that the transit measurement is more sensitive than manometry in detecting abnormal oesophageal function.

Manometric examinations carried out simultaneously with radionuclide transit studies have shown that a specific pattern of 'to and fro' movement of isotope between areas of the oesophagus occurs when non-propagated simultaneous pressure waves

Address for correspondence: Dr R C Heading. Department of Medicine. Royal Infirmary. Edinburgh E:H39YW

Received for publication 12 September 1985 are recorded manometrically after a swallow. ${ }^{+}$Such abnormalities of transit are now known to occur in symptomatic patients with normal manometry, ${ }^{12}$ as well as in those with manometric evidence of diffuse oesophageal spasm. Based on these considerations, we believe that 'to and fro' activity observed during a delayed radionuclide transit study suggests oesophageal spasm, even where resting manometry is normal.

The aim of the present study is to assess the diagnostic yield and clinical value of radionuclide transit studies in the assessment of 150 consecutive patients undergoing oesophageal motility studies for diagnostic purposes.

\section{Methods}

PATIENTS

One hundred and fifty patients were referred for clinical evaluation of oesophageal motility. There were 81 men and 69 women, average age 47.5 years (range 18-73 years). The principal symptoms leading to referral were as follows: non-cardiac chest pain (55), chest pain and dysphagia (16), dysphagia alone (35), heartburn (21), heartburn and dysphagia (nine), vomiting and regurgitation (eight), epigastric pain (six). 
At least one of either endoscopy or conventional barium radiology of the oesophagus and stomach was done before motility studies to exclude obstructive oesophageal lesions and to examine for signs of gastro-oesophageal reflux disease. Radiological technique included as assessment of three swallows of barium in the erect position and an examination with the patient supine, during which manoeuvres were undertaken to examine for gastrooesophageal reflux. Both endoscopy and radiological studies were carried out in 120 patients, while 23 patients underwent endoscopy alone and seven patients barium studies alone. We did not insist on radiological examination in all our patients (provided endoscopy had been carried out) in view of our previous disappointing results with radiology in the assessment of oesophageal dysmotility. ${ }^{2}$

All patients then underwent radionuclide transit measurements and oesophageal manometry. Sixty patients also had prolonged oesophageal $\mathrm{pH}$ recordings.

\section{MANOMETRIC TECHNIQUE}

Oesophageal manometry was conducted using an Arndorfer ESM3 8-lumen polyvinyl naso-oesophageal tube of $4.8 \mathrm{~mm}$ external diameter, each lumen having a side opening of $0.8 \mathrm{~mm}$ diameter. Each lumen was perfused with water at a constant rate of $0.7 \mathrm{ml}$ per minute by an Arndorfer capillary infusion pump. Pressure changes were detected by pressure transducers (Elcomatic EM750) connected by amplifier modules (Elcomatic EM760) to a chart recorder (Elcomatic EM740). This system has a response rate of $250 \mathrm{mmHg} / \mathrm{second}$.

Using three distally opening lumens, $1 \mathrm{~cm}$ apart, and orientated radially at $120^{\circ}$ to one another, the lower oesophageal sphincter pressure was estimated three times for each individual by the rapid pullthrough technique. Distal oesophageal peristalsis was assessed using three lumens at $5 \mathrm{~cm}$ intervals, with the distal opening positioned $5 \mathrm{~cm}$ above the distal end of the sphincter. Motility was then assessed in response to 15 swallows of $5 \mathrm{ml}$ water administered from a syringe at 20 second intervals with the patient recumbent. Average distal peristaltic amplitude and duration was calculated from the last five wet swallows in each case.

\section{SCINTIGRAPHIC TECHNIQUE}

Radionuclide transit studies were carried out as described previously. ${ }^{2}$ Each patient was examined supine, and asked to swallow $10 \mathrm{ml}$ of water containing $18.5 \mathrm{MBq}$ of $99 \mathrm{~m}$ technetium sulphur colloid introduced into the mouth from a syringe, and then to 'dry swallow' at 30 second intervals for two minutes. Multiple images $(2 /$ second) of the oesophagus were recorded by a gamma camera fitted with a diverging collimator, and linked to a computer. The examination was repeated with a second technetium swallow in each case.

A graphic display of the transit pattern through each third of the oesophagus was generated, and the total transit time calculated as the time from the first appearance of radionuclide in the proximal oesophagus to disappearance of all but $10 \%$ of activity from the distal third of the oesophagus.

\section{PH STUdiES}

Prolonged intraoesophageal $\mathrm{pH}$ monitoring was carried out in 60 patients. Of these, 11 had 15 hour overnight recordings and 49 underwent ambulatory 23 hour monitoring. For the latter, a naso-oesophageal glass $\mathrm{pH}$ electrode (Ingold $\mathrm{pH}$ electrode, Pye-Unicam, UK) was positioned $5 \mathrm{~cm}$ above the distal end of the lower oesophageal sphincter previously determined by manometry. Recordings were made on a modified Holter cassette recorder carried by the patient on a belt. Patients were allowed to go home if they wished, and no restrictions were made on activities or food and drink ingestion. Each patient kept a record of symptoms, posture, and food or drink ingestion. Before and after each study, the $\mathrm{pH}$ probe was calibrated against a range of buffers, but in no case did the $\mathrm{pH}$ drift by more than 1 unit.

For the purposes of this study, recordings demonstrating greater than $4.2 \%$ of the recording time with distal oesophageal $\mathrm{pH}$ less than 4 were deemed to show significant reflux.

\section{MANOMETRIC AND RADIONUCLIDE TRANSIT}

ANALYSIS

Manometric abnormalities were classified using criteria suggested by Benjamin et $a t^{t}$ and the range of normal values reported by Nelson et al $^{7}$ working with apparatus comparable to our own.

Radionuclide studies were reported independently by two observers (RDA and JNB) who were not given access to clinical information or the results of other investigations, apart from knowing whether or not a hiatal hernia had been shown endoscopically or radiologically. ${ }^{8}$ The total transit time (normal $<15 \mathrm{sec}$ ) and any abnormality of the pattern of transit were noted. ${ }^{2}$ The principal abnormalities seen were either static retention, or incoordination with 'to and fro' movement of radionuclide between the distal and mid or proximal thirds of the oesophagus. Gastro-oesophageal reflux was also noted, if present. If a double swallow occurred, this was taken to invalidate the transit test. This was observed on one of the two transit measurements in five cases. The two independent observers were in 
agreement in reporting $90 \%$ of radionuclide transit studies; in the remaining $10 \%$ an agreed final report was made after the two observers jointly reviewed the time activity curves for the transit test, together with the record of oesophageal imaging in each case. $^{8}$

\section{Results}

For each patient, a final diagnosis was reached after consideration of the clinical features and the results of all investigations. Thus, motility disturbances were diagnosed on the basis of appropriate clinical features, together with manometric or radionuclide transit abnormalities or both. Radiological findings (considered separately later in this report) suggesting a motility disturbance did not form the sole basis for the diagnosis of the motility disorder in any case. The diagnosis of gastro-oesophageal reflux disease was based on one or more of the following findings: endoscopic oesophagitis, free radiological reflux of barium or abnormal acid reflux during prolonged $\mathrm{pH}$ monitoring.

The final diagnoses reached were as follows: 33 patients had a normal oesophagus; 50 had a primary oesophageal motility disorder including: diffuse oesophageal spasm (22), achalasia (10), hyper-

Table 1 Abnormal manometry in 26 patients with normal radionuclide transit measurements

Diffuse ocsophageal spasm

Hypertensive lower oesophageal sphincter

'Nutcracker' oesophagus

Non-specific oesophageal motility disorders

(low amplitude peristalsis

Adynamic distal oesophagus

Frequent non-conducted swallow

2) tensive lower oesophageal sphincter (seven), nutcracker oesophagus (one), and non-specific oesophageal motility disorders (10). A total of 50 patients had gastro-oesophageal reflux disease. Twenty seven of these had associated manometric abnormalities, including: hypertensive lower oesophageal sphincter (five), nutcracker oesophagus (three), diffuse oesophageal spasm (three), and non-specific oesophageal motility disorders (12). A further four patients with gastro-oesophageal reflux had normal manometry but prolonged radionuclide transit, including three which showed 'to and fro' movement of isotope.

Secondary motility disorders were diagnosed in 12 patients. These motility disorders were secondary to surgery (eight), scleroderma (one), intestinal pseudo-obstruction resulting from a collagen disorder (one), aortic compression of the distal oesophagus (one), and carcinoma of the cardia (one).

Five patients had miscellaneous conditions. including rumination (two), oesophageal varices (one); two patients had previously dilated strictures and recurrent dysphagia but no radiological or endoscopic evidence of recurrent stricture.

CONCORDANCE BETWEEN INVESTIGATIONS

Radionuclide transit and manometry were both normal in 59 patients, and both were abnormal in 47. There was, therefore, agreement in 106 of 150 patients $(71 \%)$. Disparity was observed in 44 patients $(29 \%)$. Of these 44,26 had abnormal manometry but normal radionuclide transit measurements, and 18 had normal manometry but abnormal radionuclide transit studies.

The final diagnoses in the group of 26 patients with abnormal manometry and normal radionuclide transit measurements is summarised in Table 1 . It is of interest that this group includes all four patients

Table 2 Presenting symptoms, final diagnoses and pattern of radionuclide transit abnormality in 18 patients with normal manometry

\begin{tabular}{|c|c|c|}
\hline $\begin{array}{l}\text { Presenting symptoms } \\
\text { (No of patients in parentheses) }\end{array}$ & Final diagnosis & Transit abnormality \\
\hline $\begin{array}{l}\text { Chest pain (6) } \\
\text { Epigastric pain (1) }\end{array}$ & Oesophageal spasm & 7-incoordination \\
\hline $\begin{array}{l}\text { Chest pain (3) } \\
\text { Dysphagia, heartburn (1) }\end{array}$ & Reflux associated motility disorder & $\begin{array}{l}\text { 3-incoordination } \\
1 \text {-static retention }\end{array}$ \\
\hline Dysphagia, odynophagia (1) & $\begin{array}{l}\text { Secondary motility disorder (aortic } \\
\text { compression of oesophagus) }\end{array}$ & Incoordination \\
\hline $\begin{array}{l}\text { Chest pain (2) } \\
\text { Chest pain }+ \text { dysphagia ( } 1 \text { ) } \\
\text { Epigastric pain (1) } \\
\text { Dysphagia (1) }\end{array}$ & Non-specific motility disorders & 5 -static retention \\
\hline Recurrent dysphagia (1) & $\begin{array}{l}\text { 'Functional' stricture (previous } \\
\text { stricture no longer demonstrable) }\end{array}$ & Static retention \\
\hline
\end{tabular}


with a manometric pattern of high amplitude or prolonged duration peristalsis ('nutcracker'), and 10 of 14 patients with hypertensive lower oesophageal sphincter. In addition, seven patients with oesophageal spasm had normal radionuclide transit.

Eighteen patients with normal manometry had abnormalities of radionuclide transit (Table 2). Of these, 11 showed an incoordinate pattern suggestive of oesophageal spasm (Fig. 1), three in association with gastro-oesophageal reflux disease. The remaining seven had distal static retention (Fig. 2), comprising five patients with otherwise unexplained chest or epigastric pain, one of whom also had dysphagia, and a further two patients with otherwise unexplained dysphagia.

\section{DETECTION OF DYSMOTILITY BY RADIONUCLIDE TRANSIT}

All patients with achalasia (10 cases) were detected by both manometry and radionuclide transit. The radionuclide transit study in eight showed static retention for greater than 120 seconds, the remaining two also demonstrating incoordinate activity (Fig. 3), one of whom had a manometric pattern of vigorous achalsia.

Twenty two patients were diagnosed as primary diffuse oesophageal spasm. Of these, 10 had both abnormal manometry and radionuclide transit, while five had manometric abnormalities only and seven had incoordinate activity on the radionuclide transit study but normal manometry. In all, 17 patients in this group of 22 had an abnormal radionuclide transit while 15 had abnormal manometry. The detection rate is similar for both tests (difference not significant; $\chi^{2}=0 \cdot 11$, Yates corrected).

Motility disorders associated with gastro-oesophageal reflux were diagnosed in 27 patients. If those patients with raised lower oesophageal sphincter pressure (five patients) and prolonged amplitude or duration of peristalsis (three patients) are excluded, manometry detected 15 and transit measurement 14 of the 19 with dysmotility. The detection rate of motility disorder excluding the two categories mentioned above is similar (difference not significant; $\chi^{2}=0 \cdot 0$, Yates corrected).

Abnormal radionuclide transit measurements were observed in 10 of the 12 patients with secondary motility disorders, the two normal transit studies being in those patients in whom a raised lower oesophageal sphincter pressure was the only manometric abnormality.

ROLE OF ENDOSCOPY AND BARIUM RADIOLOGY Endoscopy was carried out in 143 patients. Oesophagitis was detected in 38 patients, eight of whom
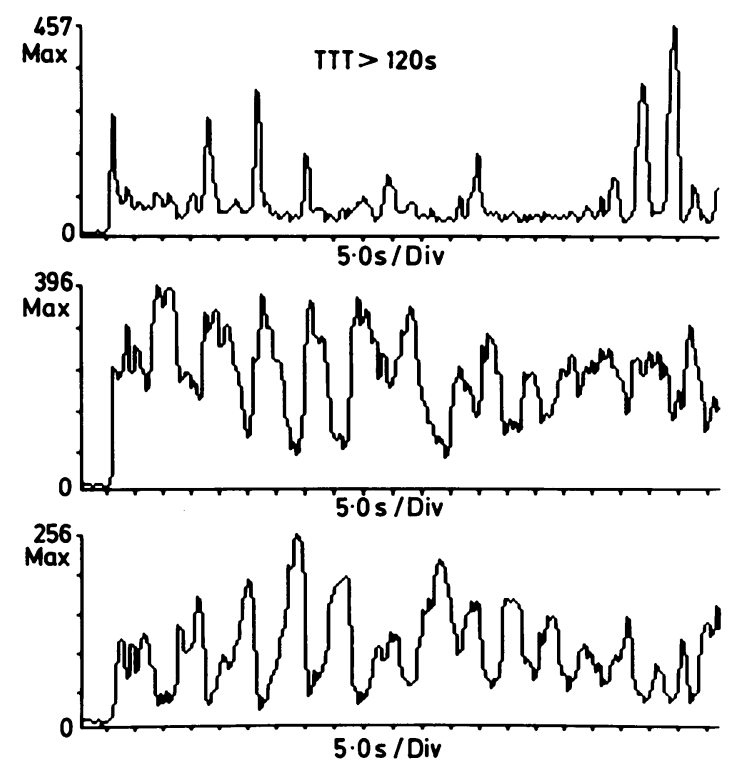

Fig. 1 Radionuclide time activity curves showing 'to and fro' movement of isotope between distal and middle oesophagus. Radioactivity counts in proximal, middle and distal thirds of oesophagus on vertical axis; time in seconds on horizontal axis.
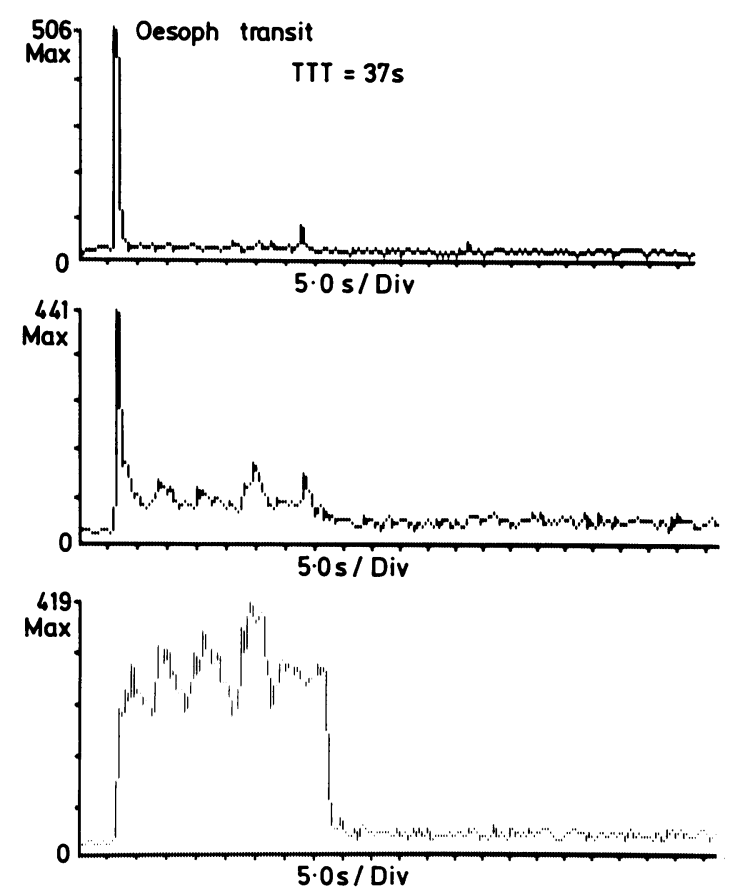

Fig. 2 Radionuclide time activity curves demonstrating distal static retention for less than 40 seconds. Axes as for Figure 1. 

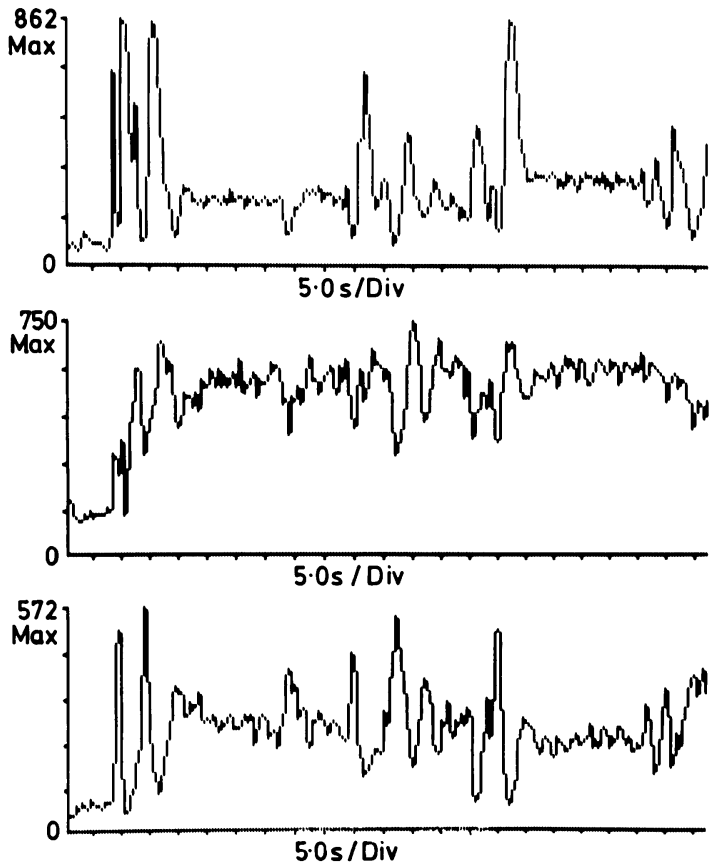

Fig. 3 Radionuclide time activity curves from a patient with vigorous achalasia, showing marked isotope retention within the oesophagus, with some 'to and fro' intraoesophageal movement of isotope. Axes as for Figure 1 . had a Barrett's oesophagus. In nine of these patients who did not undergo oesophageal $\mathrm{pH}$ monitoring, gastro-oesophageal reflux disease was diagnosed on the basis of endoscopic oesophagitis alone. Other endoscopic findings included a dilated oesophagus in six (four with achalasia, two with secondary motility disorders), carcinoma of the cardia (one), varices (one), epiphrenic diverticulae (one), and gastric ulcer (three).

Conventional barium radiology was undertaken in 127 patients. Gross free gastro-oesophageal reflux was observed in 16 and was the diagnostic finding in one patient with gastro-oesophageal reflux disease who did not undergo prolonged $\mathrm{pH}$ monitoring. Mild reflux was occasionally observed during other studies but was not of itself regarded as significant.

In 28 patients, abnormalities were observed which were thought to represent a motor disturbance by the examining radiologist. One of these patients, with radiological diagnosis of achalasia, was subsequently found to have carcinoma of the cardia at endoscopy and a non-specific oesophageal motor disorder by manometry. Of the 10 patients with achalasia, nine had abnormal barium studies which were regarded as showing achalasia in five and distal oesophageal obstruction with the cause not specified in four. In a further patient with typical achalasia on manometric and radionuclide studies, the diagnosis was missed by radiological examination.

Twenty of the 22 patients with a final diagnosis of

Table 3 Comparison of barium radiology, radionuclide transit and manometry in the detection of specific oesophageal motor disorders

\begin{tabular}{|c|c|c|c|c|c|c|c|c|}
\hline & $\begin{array}{l}\text { Abnormal } \\
\text { manometry+ } \\
\text { radionuclide } \\
\text { transit }\end{array}$ & $\begin{array}{l}\text { Abnormal } \\
\text { manometry } \\
\text { only }\end{array}$ & $\begin{array}{l}\text { Abnormal } \\
\text { radionuclide } \\
\text { transit only }\end{array}$ & $\begin{array}{l}\text { Both } \\
\text { normal }\end{array}$ & $\begin{array}{l}\text { Abnormal } \\
\text { manometry+ } \\
\text { radionuclide } \\
\text { transit }\end{array}$ & $\begin{array}{l}\text { Abnormal } \\
\text { manometry } \\
\text { only }\end{array}$ & $\begin{array}{l}\text { Abnormal } \\
\text { radionuclide } \\
\text { transit only }\end{array}$ & $\begin{array}{l}\text { Both } \\
\text { normal }\end{array}$ \\
\hline & \multicolumn{4}{|c|}{ (i) Achalasia (10) } & \multicolumn{4}{|c|}{ (v) Non-specific oesophageal motility disorders (10) } \\
\hline $\begin{array}{l}\text { Abnormal } \\
\text { Barium }\end{array}$ & 9 & - & - & - & - & - & 1 & - \\
\hline Normal & 1 & - & - & - & 3 & 2 & 4 & - \\
\hline $\begin{array}{l}\text { Abnormal } \\
\text { Barium }\end{array}$ & $\begin{array}{l}\text { (ii) Diffuse } \\
5\end{array}$ & $\begin{array}{l}\text { esophageal sp } \\
1\end{array}$ & $m_{1}(20)$ & - & $\begin{array}{l}\text { (vi) Secondar } \\
4\end{array}$ & y motility dis & $\begin{array}{l}\text { rders }(10) \\
1^{*}\end{array}$ & - \\
\hline Normal & \multicolumn{4}{|c|}{ (iii) Hypertensive lower oesophageal sphincter (10) } & \multicolumn{4}{|c|}{ (vii) Reflux associated motility disorders (15) } \\
\hline \multicolumn{9}{|l|}{ Barium } \\
\hline Normal & \multicolumn{4}{|c|}{ (iv) Nutcracker ocsophagus (4) } & \multicolumn{4}{|c|}{$\begin{array}{l}\text { (viii) Normal oesophagus/reflux without motility } \\
\text { disorder (48) }\end{array}$} \\
\hline $\begin{array}{l}\text { Ahnormal } \\
\text { Barium }\end{array}$ & - & - & - & - & - & - & - & 4 \\
\hline Normal & - & 4 & - & - & - & - & - & 44 \\
\hline
\end{tabular}

Note: Only 127 patients who underwent barium studies are included.

${ }^{*}$ These patients had manometric and/or radionuclide transit studies suggestive of diffuse oesophageal spasm. 
Table 4 Comparison of radiology, radionuclide transit and manometry in the detection of oesophageal motor disorders in 127 patients undergoing barium studies

\begin{tabular}{|c|c|c|c|c|c|c|}
\hline & \multicolumn{2}{|c|}{ Manometry } & \multicolumn{2}{|c|}{ Radionuclide transit } & \multicolumn{2}{|l|}{ Both/either } \\
\hline & Abnormal & Normal & Abnormal & Normal & Abnormal & Normal \\
\hline Abnormal & 22 & 6 & 23 & 5 & 24 & 4 \\
\hline \multicolumn{7}{|l|}{ Barium } \\
\hline Normal & 40 & 59 & 35 & 64 & 55 & 44 \\
\hline Sensitivity of radiology & \multirow{2}{*}{\multicolumn{2}{|c|}{$35 \%$}} & \multicolumn{2}{|c|}{$40 \%$} & \multicolumn{2}{|l|}{$30 \%$} \\
\hline Specificity of radiology & & $91 \%$ & \multicolumn{2}{|c|}{$93 \%$} & \multicolumn{2}{|c|}{$92 \%$} \\
\hline
\end{tabular}

diffuse oesophageal spasm had radiological studies. Abnormalities were found in six $(30 \%)$, including tertiary waves (three), diffuse narrowing of the lower oesophagus (two) and delayed emptying of barium from the oesophagus (one). In all six cases endoscopy was normal. In no case was oesophageal spasm observed radiologically.

In the remaining patients with non-specific motility disorders, including secondary and reflux associated motility disorders, functional radiological abnormalities were seen in five including tertiary waves (one), delayed emptying of barium from the oesophagus (two), 'achalasia' (one) and dilated oesophagus (one). Three other patients with reflux related or secondary motility disorders who had manometric and/or radionuclide transit evidence of oesophageal spasm had radiological abnormalities, comprising diffusely narrowed lower oesophagus (one), delayed emptying of barium (one) and tertiary waves (one). Finally, one patient with a hypertensive lower oesophageal sphincter had tertiary waves shown radiologically, and also had an abnormal radionuclide transit (static retention) (Table 3 ).

Forty eight patients with a final diagnosis of either normal oesophagus or gastro-oesophageal reflux disease without motility disorder underwent radiological investigation. Tertiary waves were seen in 4 $(8 \%)$ but the remaining 44 had no radiological evidence of dysmotility.

The relative value of barium studies, radionuclide transit measurement and manometry in demonstrating abnormalities in specific motility disorders is displayed in Table 3. Table 4 compares the overall detection of motility disturbance by radiology, radionuclide transit measurement and manometry in 127 patients who underwent radiological studies. The sensitivity of radiology is poor and similar whether compared with manometry alone, radionuclide transit measurement alone or the combined results of both studies.

\section{Discussion}

In order to assess the clinical value of radionuclide transit studies in the identification of oesophageal motor disorders, it is necessary to compare the results of this test with the established investigations of manometry and radiology. The diagnostic yield in patients in whom conventional investigations are normal may then be assessed. We found concordance between transit studies and manometry in $71 \%$ of our patients, which is lower than in previous reports. ${ }^{12}$ The major areas of disagreement are in patients with a normally relaxing but hypertensive lower oesophageal sphincter, those with nutcracker oesophagus, and patients with conditions such as diffuse oesophageal spasm in which incoordinate motor activity of the oesophagus occurs. The reasons for these discrepancies are readily appreciated from the work of Richter and his colleagues ${ }^{4}$ who undertook radionuclide transit measurements and manometry concurrently in order to study both normal controls and patients with oesophageal motor disorders. They found that radionuclide transit time was independent of both amplitude and duration of peristaltic waves and the pressure of the lower oesophageal sphincter, provided that the wave front after a swallow was peristaltic and the lower oesophageal sphincter relaxed normally. It should come as no surprise therefore that patients with hypertensive lower oesophageal sphincter or nutcracker oesophagus frequently have normal radionuclide oesophageal transit measurements. ${ }^{9}$ Our findings, however, conflict with the results of other investigators ${ }^{10}$ who found that a proportion of patients with nutcracker oesophagus have abnormal radionuclide transit measurements. This may be explained when it is appreciated that many of their patients also had non-propagated contractions on manometry, and it is possible that these latter abnormalities were responsible for the abnormal transit measurements they observed. ${ }^{11}$

Conversely, both Richter and his colleagues using radionuclide transit ${ }^{4}$ and Roth and Fleshler using radiology with concurrent manometry ${ }^{12}$ have shown that incoordinate (or 'to and fro') movement of isotope or barium occurs in association with a nonperistaltic wave front following a swallow. Indeed, 
mutliple episodes of 'to and fro' movement of radionuclide occur during a transit measurement when a succession of non-peristaltic waves after a swallow is recorded manometrically. ${ }^{4}$ This latter abnormality constitutes good manometric evidence of oesophageal spasm, and Richter's work supports the contention that incoordinate radionuclide transit is also strongly suggestive of this condition. It is to be expected that in some patients with oesophageal spasm the radionuclide studies will be abnormal in the face of normal manometry and vice versa, as oesophageal spasm is frequently intermittent and may be present during one examination but not the other. Hence, where symptomatic patients with normal manometry were observed to have a prolonged radionuclide transit measurement with 'to and fro' movement of isotope, this was regarded as evidence of oesophageal spasm in our study (see Table 2).

A further seven symptomatic patients with normal manometry had delayed transit measurements with static retention in at least one of the two studies done on each patient (Table 2). We observed a similar abnormality in 11 patients with manometric abnormalities, principally non-specific oesophageal motility disorders. Nelson and his colleagues ${ }^{6}$ reported that only one of 50 normal subjects had an occasional wet swallow followed by a simultaneous non-peristaltic wave, but that in $22 \%$ of normal subjects up to $50 \%$ of wet swallows may not be conducted to the distal oesophagus. These two types of manometric feature, when occurring more frequently, are considered to indicate oesophageal motility disorders. It seems likely from the work of Richter and his colleagues ${ }^{4}$ that such features could lead to the abnormal transit measurements that we have observed in the seven patients noted above. It is conjecture whether such abnormalities represent true 'false positive' results or whether they are significant abnormalities, although the fact that they are seen also in some patients with a manometric abnormality suggest they may indeed be of clinical relevance.

Our results confirm the findings of others that conventional barium radiology is relatively insensitive in detecting oesophageal dysmotility. ${ }^{2} 1314$ We found that when compared with manometry, radionuclide transit or the combined results of both investigations, barium radiology has a sensitivity of $35 \%, 40 \%$, and $30 \%$ respectively in detecting dysmotility (Table 4). We also observed that tertiary waves were seen in the same proportion of those with motility disorders (six of $79-8 \%$ ) and those without motility disorders (four of $48-8 \%$ ) who underwent radiological studies. This confirms the finding of Alban-Davies and his colleagues ${ }^{13}$ that tertiary waves are a non-specific finding which do not necessarily indicate a motility disorder. It should also be noted from our results that the radiological features were only thought diagnostic in five of our patients, all of whom had achalasia. There is now some evidence that specialised radiological techniques, such as the 'bread barium' swallow ${ }^{14}$ may be of more value than conventional barium studies in the context of the diagnosis of oesophageal dysmotility.

The purpose of this study was to assess the clinical value of radionuclide transit measurements in the diagnosis of oesophageal motor disorders. Several investigations were used to assess each patient and the final diagnosis was arrived at after consideration of the clinical features coupled with the results of all investigations. This diagnosis has provided the reference against which the value of the transit measurement has been assessed. On this basis, the sensitivity of radionuclide transit measurements in detecting oesophageal dysmotility was $75 \%$, while the sensitivity for manometry was $83 \%$ and for radiology $30 \%$ (which increases to $34 \%$ if the four patients with tertiary waves but normal manometry and radionuclide transit are included as being abnormal).

In conclusion, our results show that radionuclide transit and manometry are complementary investigations, each detecting abnormalities not detected by the other. This is perhaps to be expected, because they assess different aspects of oesophageal motor function. They have similar sensitivity, however, in detecting conditions characterised by frequent non-peristaltic contractions and failure of lower oesophageal sphincter relaxation. As expected, radionuclide transit measurement usually fails to detect high amplitude and prolonged duration peristalsis ('nutcracker') and hypertensive lower oesophageal sphincter which together formed $20 \%$ of our patients with motility disorders. For this reason, radionuclide transit measurement has limitations as a screening test for oesophageal dysmotility. We have found the test more sensitive, however, than conventional contrast radiology in showing oesophageal motor disturbances.

Accurate definition of a motility disorder usually requires oesophageal manometry, but the radionuclide transit measurement can provide useful additional information about oesophageal function.

\section{References}

1 Russell COH, Hill LD, Holmes ER, Hall DA, Gannan R, Pope CE. Radionuclide transit: a sensitive screening test for esophageal dysfunction. Gastroenterology 1981; 80: $887-92$. 
2 Blackwell JN, Hannan WJ, Adam RD, Heading RC. Radionuclide transit studies in the detection of oesophageal dysmotility. Gut 1983; 24: 421-6.

3 Tolin RD, Malmud RS, Reilley J, Fisher RS. Esophageal scintigraphy to quantitate esophageal transit. Gastroenterology 1979; 76: 1402-8.

4 Richter JE, Blackwell JN, Wu WC, Cowan RJ, Johns DN, Castell DO. Assessment of liquid bolus transit by simultaneous radionuclide transit and esophageal manometry. Gastroenterology 1983; 84: 1285.

5 Demeester TR, Wang CI, Wernly JA, et al. Technique, indications, and clinical use of 24 hour esophageal $\mathrm{pH}$ monitoring. J Thorac Cardiovasc Surg 1980; 79: 656-70.

6 Benjamin SB, Richter JE, Cordova CM, Knuff TE, Castell DO. Prospective manometric evaluation with pharmacological provocation of patients with suspected esophageal motility dysfunction. Gastroenterology 1983; 84: 893-901.

7 Nelson JL, Wu WC, Richter JE, Blackwell JN, Johns DN, Castell DO. What is normal esophageal motility? Gastroenterology 1983; 84: 1258.

8 Blackwell JN, Richter JE, Wu WC, Cowan RJ, Castell
DO. Esophageal radionuclide transit tests: potential false positive results. Clin Nucl Med 1984; 9: 679-83.

9 Blackwell JN, Castell DO. Esophageal Radionuclide Transit Studies. In: Dubois A, Castell DO, eds. Esophageal and gastric emptying. Florida: CRC Press, 1984: 29-36.

10 Benjamin SB, Odonnell JK, Nielsen P, Castell DO. Prolonged radionuclide transit in the nutcracker esophagus. Dig Dis Sci 1983; 28: 775-9.

11 Richter JE, Wu WC, Cowan RJ, Ott DJ, Blackwell JN. Nutcracker oesophagus. [Letter]. Dig Dis Sci 1985; 30: 88.

12 Roth HP, Fleshler B. Diffuse esophageal spasm, radiological and manometric observations. Ann Intern Med 1964; 61: 914-22.

13 Alban Davies H, Kaye MD, Rhodes J, Dart AM, Henderson AH. Diagnosis of esophageal spasm by ergometrine provocation. Gut 1982; 23: 89-97.

14 Alban Davies H, Evans KT, Butler F, McKirdy H, Williams GT, Rhodes J. Diagnostic value of "bread barium" swallow in patients with esophageal symptoms. Dig Dis Sci 1983; 28: 1094-100. 